Article

\title{
Cropping System Redesign for Improved Weed Management: A Modeling Approach Illustrated with Giant Ragweed (Ambrosia trifida)
}

\author{
Matt Liebman * and Virginia A. Nichols $\mathbb{D}$ \\ Department of Agronomy, Iowa State University, Ames, IA 50011-1051, USA; vnichols@iastate.edu \\ * Correspondence: mliebman@iastate.edu; Tel.: +1-515-294-7486
}

Received: 6 January 2020; Accepted: 10 February 2020; Published: 12 February 2020

\begin{abstract}
Weeds present important challenges to both conventional farmers who rely on herbicides and organic farmers who rely on cultivation. Data from field experiments indicate that diversifying crop sequences with additional species can improve weed suppression when either herbicides or cultivation serve as primary control tactics. Here, we report the results of modeling analyses that investigated how cropping system diversification would affect the population dynamics of giant ragweed (Ambrosia trifida L.), an annual dicotyledonous species that is problematic in the central U.S. for both conventional and organic farmers. We found that to prevent an increase in giant ragweed density, the minimum control efficacy needed from herbicides or cultivation used in corn (Zea mays L.) and soybean (Glycine $\max$ (L.) Merr.) would be $99.0 \%$ in a 2-year corn-soybean system, but $91.4 \%$ in a 5-year corn-soybean-rye (Secale cereale L.)-alfalfa (Medicago sativa L.) system. Thus, the diversified rotation would be better buffered against less-than-perfect weed control during corn and soybean phases. Further modeling analyses indicated that the weed suppression effect associated with greater rotation length was attributable not only to increased crop species richness but also to greater temporal variation in planting dates. A planting interval variation index (PIVI), calculated as the coefficient of variation in months between planting activities, was strongly associated with the weed suppressive ability of the rotations we modeled and may be a useful metric for designing other cropping systems. Overall, our results indicate that diversified rotation systems that include both annual and perennial crops are likely to be valuable for managing problematic weed species.
\end{abstract}

Keywords: crop rotation; giant ragweed; Ambrosia trifida; weed management; population dynamics models

\section{Introduction}

\subsection{Overview}

Despite the use of large amounts of technology and labor for weed control, weeds remain a recurrent and substantial threat to crop production and farm profitability in both developed and developing countries [1]. For conventional farmers who rely heavily on herbicides for weed suppression, herbicide resistance in weed populations and off-site movement of herbicides in air and water pose increasing challenges [2-4]. For organic farmers and others who eschew the use of herbicides, weather conditions that prevent timely field operations and lower levels of efficacy with cultivation relative to herbicides comprise serious impediments to successful weed control $[5,6]$. For both conventional and organic farmers, durable improvements in weed management are likely to be based on knowledge of ecological principles and processes, elucidation of the life history characteristics of problematic weed species, evaluation of management options through population dynamics modeling and other approaches, and the use of multi-tactic management strategies [7-10]. 
Cropping system diversification is considered by many analysts to be a critically important element of improved weed management systems [11,12]. Liebman and Gallandt [13] suggested that through use of diverse sets of crops that differ with regard to planting and harvest dates and attendant management practices, weeds can be challenged by a wide array of stress and mortality factors. This diversification should reduce selection of weed populations for resistance, limit shifts in weed community composition toward especially problematic species, and minimize the risks of weed control failures due to mitigating factors such as weather conditions [13]. In a recent meta-analysis of data from field experiments, Weisberger et al. [14] found that diversifying crop rotation sequences with additional species reduced weed densities by an average of $49 \%$, regardless of auxiliary herbicide use. Furthermore, the diversification effect on weed density was greatest for rotation sequences with the largest variance around crop planting dates. Previously, Gaba et al. [15] had noted that the effects of different cropping systems on weed dynamics could be captured by quantifying the magnitude of changes in sowing dates between successive crops.

Here, we report the results of modeling analyses conducted to investigate how specific forms of cropping system diversification would affect the population dynamics of giant ragweed (Ambrosia trifida L.), a species that is problematic in the central U.S. for both conventional and organic farmers. Our analyses were intended to be heuristic. That is, we used models to describe what would happen if our assumptions held, rather than what will happen at all times and places. As noted by Levins [16], such models cannot provide precise location- and time-specific descriptions but can be realistic and useful for gaining insight into the dynamics of populations of interest.

\subsection{Giant Ragweed (Ambrosia trifida L.)}

Giant ragweed is an annual dicotyledonous species native to North America. In a survey of certified crop advisors, giant ragweed was noted as the most, or one of the most, difficult weeds to manage in a large number of counties in the U.S. Corn Belt [17]. Many respondents also reported that populations of the weed were resistant to acetolactate synthase inhibitors, glyphosate, or both herbicide chemistries [17].

In addition to herbicide resistance, a number of ecological characteristics contribute to this species' ability to compete strongly with the two dominant crops in the central U.S., corn (Zea mays L.) and soybean (Glycine max (L.) Merr.). Key characteristics include large seeds with substantial energy reserves that permit emergence from deeper soil layers; early initiation of seedling emergence; cold tolerance by seedlings; large cotyledons that allow for substantial carbon gain immediately after seedling emergence; and rapid leaf production and stem growth that promote overtopping and shading of associated crop plants [18]. In addition, there now appears to be selection for extended periods of giant ragweed seedling emergence, rather than synchronized early emergence, which makes control more challenging, as a single pre-plant tillage pass or early season herbicide application may no longer suffice to reduce giant ragweed densities [17].

Despite the set of ecological characteristics that make giant ragweed difficult to manage, especially in corn and soybean fields, the species has a number of characteristics that can render it vulnerable to control. Compared with other weed species, giant ragweed fecundity is relatively low, with an individual plant producing one to two thousand seeds, rather than tens of thousands or hundreds of thousands of seeds $[19,20]$. Seeds are not dispersed from parent plants until late summer and fall $[19,20]$, making mid-summer destruction of plants an effective means of minimizing seed inputs to the soil seed bank. Large numbers of giant ragweed seeds that are shed can be consumed by rodents, invertebrates, and birds before entering the seed bank. Harrison et al. [21] reported that $60 \%$ of giant ragweed seeds were removed from the soil surface between November and May; total seed removal by predators over a 12 -month period was $88 \%$. Seeds that survive predation can be short-lived: Harrison et al. [22] noted that $~ 90 \%$ of giant ragweed seeds buried in the top $10 \mathrm{~cm}$ of soil were eliminated by decay or predation after two years. For giant ragweed seeds that do not decay or that are not 
consumed, most emergence of seedlings occurs within the first two years after seed deposition [22,23], making this species transient, rather than persistent, in the soil seed bank.

\subsection{Options for Cropping System Redesign in the U.S. Corn Belt}

One of the most striking land-use trends in the central U.S. since the Second World War is the simplification of cropping systems toward dominance by corn and soybean [24,25]. For example, between 1949 and 1997 in Iowa's Raccoon River watershed, the percentage of all cropland used for wheat, barley, oat, alfalfa, and other forage crops fell from $42 \%$ to $3 \%$, whereas the percentage in corn and soybean grew from $57 \%$ to $97 \%$ [26]. In 2017, $85 \%$ of the total harvested cropland in the states of Illinois, Indiana, Iowa, Minnesota, Nebraska, Ohio, South Dakota, and Wisconsin was occupied by corn and soybean [27]. Loss of cropping system diversity in the U.S. Corn Belt, especially the massive reduction in area used for small grains and perennial forage crops, has been linked to a variety of negative environmental effects. These include greater discharge of nitrogen and phosphorus to surface waters [26,28], increased levels of soil erosion [29], and loss of soil organic carbon [24].

At a systems level, loss of small grains and forages has been linked to a de-coupling of crop and ruminant livestock production. Sulc and Tracy [30] noted that from 1945 to 2000, cattle numbers across Ohio, Indiana, Illinois, Iowa, Wisconsin, and Minnesota declined by $52 \%$ as beef production shifted westward, while land producing hay and oat, used to feed cattle and other livestock, declined by $60 \%$ and $97 \%$, respectively. These historical shifts in crop and livestock production reflect the influence of multiple factors, including low costs for fertilizers, changes in livestock feeding regimes, increased efficiencies of scale, federal policies such as commodity support programs, shifts in public and private research priorities, and a lack of recognition of, and economic costs for, a wide range of environmental and social effects [24].

Low profitability of the dominant corn-soybean system and growing concerns over soil and water quality have led to reconsideration of the use of forage legumes and small grains within integrated crop-livestock systems in the U.S. Corn Belt [26,30]. Recent studies indicate that diversified cropping systems that include forages and small grains in addition to corn and soybean can match or exceed the profitability of simpler corn-soybean rotations [31-33] while reducing soil loss, nutrient discharge, greenhouse gas emissions, $\mathrm{PM}_{2.5}$ and precursor emissions, and herbicide-related aquatic toxicity [33-35].

In the present study, we focused on the weed-related effects of diversifying corn-soybean rotations with rye (Secale cereale L.) and alfalfa (Medicago sativa L.). Rye has excellent winter-hardiness and new, hybrid varieties have higher yield potential and lower disease susceptibility compared with older, non-hybrid cultivars [36-38]. Rye grain can be used in livestock rations to replace wheat and corn $[39,40]$. Alfalfa is widely adapted, high in protein, effective in its fixation of atmospheric nitrogen, frugal in its requirements for fossil energy, and attractive to bees as a source of nectar [41]. In 2017, alfalfa occupied $49 \%$ of the forage crop area in the states of Illinois, Indiana, Iowa, Minnesota, Nebraska, Ohio, South Dakota, and Wisconsin [27]. The use of winter cereals, like rye, and perennial forages, like alfalfa, appears to offer considerable opportunities to suppress populations of giant ragweed, due to differences in phenology and crop-specific mowing and herbicide regimes [17,32,42]. Additionally, because alfalfa is a perennial species that may remain in a field for forage harvesting for varying lengths of time after planting, modeling its use in different rotations provided an opportunity to investigate the weed-related effects of altering planting patterns without a concomitant increase in crop species richness.

\section{Model Development and Evaluation}

\subsection{Cropping System Characteristics}

We investigated cropping system effects on the population dynamics of giant ragweed using difference equation models corresponding to two-crop (corn and soybean) and a set of four-crop 
(corn, soybean, rye, and alfalfa) rotations. We constructed the four-crop rotation systems with varying durations of the alfalfa phase, resulting in rotation lengths varying from three to six years (Figure 1). The different cropping systems we investigated were intended to be appropriate for the central U.S. Corn Belt. Consequently, we assumed (1) corn and soybean were planted in April and May, respectively, and harvested in the following fall (October and September, respectively); (2) rye was planted in September immediately following soybean and harvested for grain and straw in June of the following year; and (3) alfalfa was planted in August following rye harvest and then cut, baled, and removed multiple times during each of the subsequent years, with the exception of the 3-year system, in which alfalfa was assumed to be used only as an unharvested cover crop. We recognize that the latter scenario is not economically advantageous, but it formed a useful component of our modeling analyses.

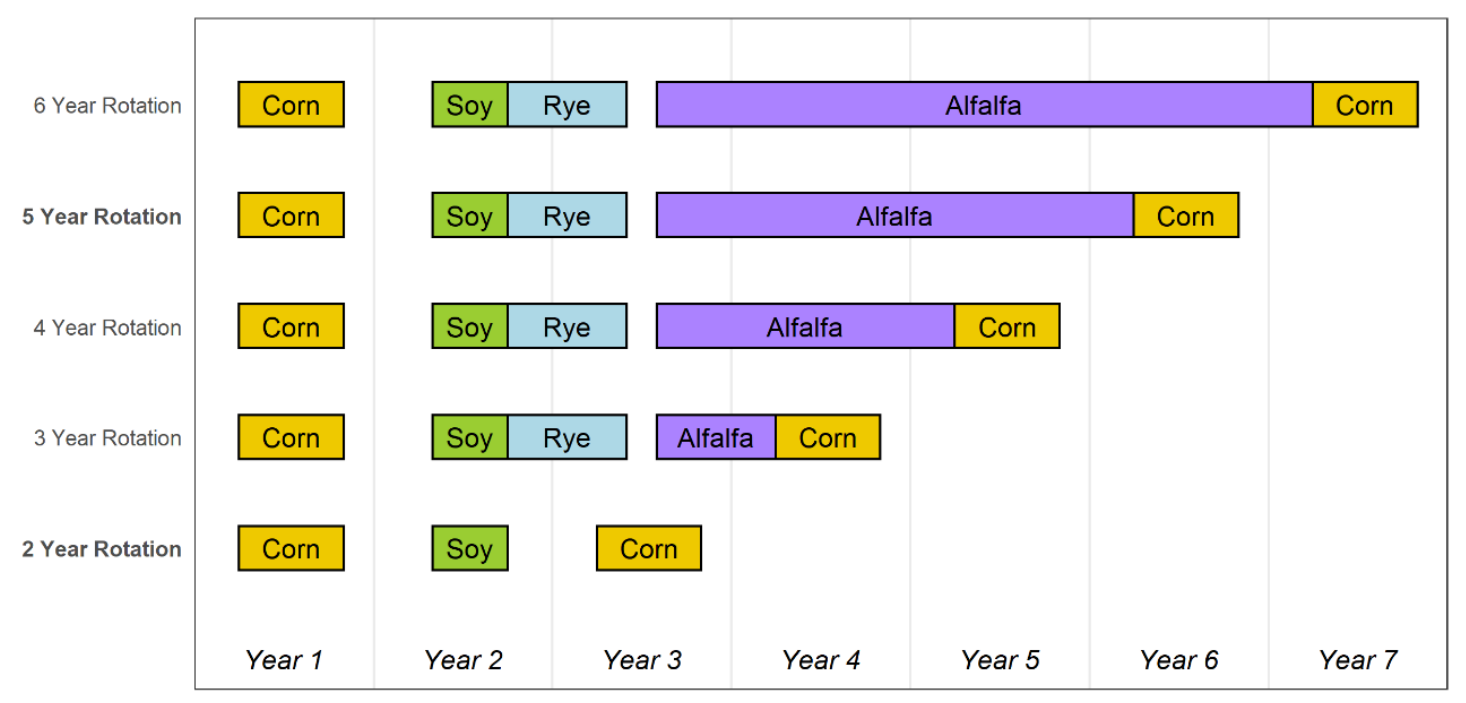

Figure 1. Crop sequences and the timing from planting to harvest or termination for 2-year and 5-year rotations (bolded) used for primary analyses, and 3-, 4-, 5-, and 6-year rotations used for secondary analyses.

\subsection{Model Concept and Structure}

We constructed population dynamics models for giant ragweed in Stella Professional 1.6 (Isee Systems, Lebanon, NH, USA). The models included stocks for four life history stages of the weed (seeds in soil, small seedlings, large seedlings, and mature plants) and seven flows or processes (seedling emergence, small seedling survival, large seedling survival, seed production, mature plant senescence, post-dispersal seed predation, and seed decay) (Figure 2). Management factors represented in the models include the efficacy of herbicide applications or cultivation during row-crop (i.e., corn and soybean) and winter cereal (i.e., rye) phases of the rotations, and hand weeding or mowing efficacy for control of giant ragweed during any phase of the rotations. The models were constructed such that crop phases followed sequentially from year to year. This made it possible for weed fecundity and the efficacy of weed control via herbicides, cultivation, hand weeding, and mowing to be crop-specific. 


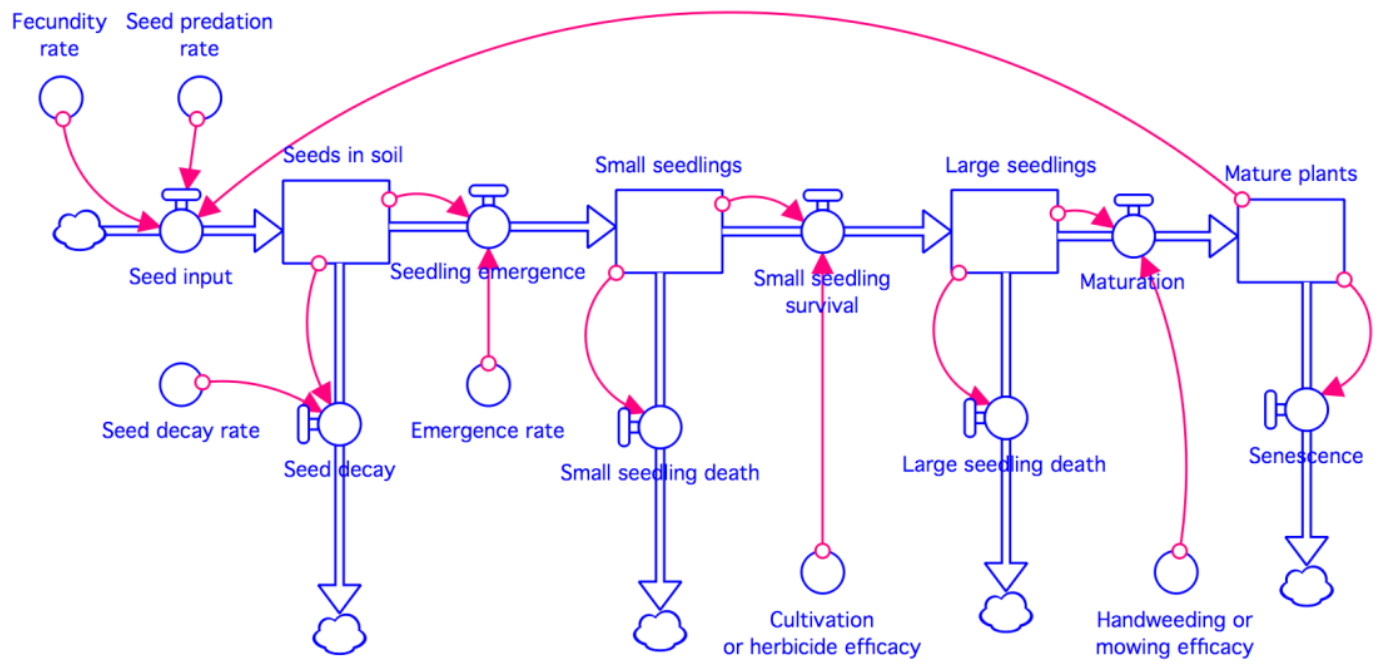

Figure 2. General model for evaluating giant ragweed population dynamics in 2-, 3-, 4-, 5-, and 6-year rotation systems. Details of models for specific rotations are provided in the Supplementary Materials.

The models were set with four time-steps per year. Seedling emergence occurred once per yearly cycle at the first time-step; small seedlings survived or died at the second time-step; and large seedlings matured or died at the third time-step. Mature plants produced seeds and then died at the fourth time-step, with the number of seeds entering the soil seed bank diminished by seed predation at that time. The decay of seeds in the soil seed bank occurred at all time-steps.

The initial stock of seeds in the soil seed bank was set at 100 viable seeds $\mathrm{m}^{-2}$; initial values of other stocks were set to 0 . We assumed that minimum- or surface-tillage techniques would be used and that weed seeds would be maintained at shallow depths from which giant ragweed seedlings could emerge. Therefore, tillage operations with attendant seed redistributions were not included in the model, and no depth structure was used for the soil seed bank.

Diagrams and equations for models of the 2-year and 5-year cropping systems with baseline parameters are shown in the Supplementary Materials (Tables S1 and S2, Figures S1 and S2).

\subsection{Giant Ragweed Demographic Parameters}

Demographic parameters for giant ragweed growing in association with different crops were drawn from published scientific reports, or, in some cases, estimated using relevant scientific literature. Because density-dependent effects on survival and fecundity were not available for giant ragweed growing with the set of crops we evaluated, we did not include them in our models. Additionally, we assumed that farmers typically impose management to maintain weed populations below levels at which intraspecific interactions affect survival and fecundity.

For convenience, we refer to control efficacy in terms of the percentage of a weed seedling population that is killed. However, from a modeling perspective, control efficacy is a rate defined in units of seedlings seedling ${ }^{-1}$. Likewise, we have expressed rates of seedling emergence (seedlings seedling ${ }^{-1}$ ) and predation and decay (seeds seed ${ }^{-1}$ ) as percentages for ease of interpretation.

We set the rate of giant ragweed seedling emergence from the soil seed bank at $18 \%$, based on the findings of Harrison et al. [22]. This value lies well within the range $(6 \%$ to $45 \%)$ reported by Wortman et al. [43] for giant ragweed seedling emergence across 34 site-year combinations in the north-central U.S. We did not use crop-specific seedling emergence rates, as Goplen et al. [23] had reported no differences in giant ragweed emergence among different crops in the first year after seed deposition.

The fecundity of giant ragweed plants growing with corn and soybean was set at 985 and 1400 viable seeds plant ${ }^{-1}$, respectively, based on values reported by Harrison et al. [19] and Goplen et al. [20]. Fecundity of giant ragweed plants growing in the post-harvest stubble of winter rye was set at 3 seeds 
plant $^{-1}$, based on values for total mass of seeds plant ${ }^{-1}$ [44], mass per seed [45], and proportion of total seeds produced that are viable [20]. Fecundity of giant ragweed growing with alfalfa, which would be cut for hay and removed multiple times per season, was assumed to be 0 .

Consumption of giant ragweed seeds shed onto the soil surface by predators (e.g., insects, rodents, birds) from late fall until spring was set at $60 \%$, based on results of experiments conducted by Harrison et al. [21] in cornfields under no-tillage management. This value is within the wide range of giant ragweed seed predation rates reported by Davis et al. [46] from experiments conducted in corn, soybean, wheat, and clover fields. We did not use crop-specific rates of seed predation, as Davis et al. [46] reported that different crops had negligible effects upon long-term seed predation rates.

Davis et al. [47] reported that $~ 90 \%$ of giant ragweed seeds buried at $2 \mathrm{~cm}$ depth decayed in two years, which is similar to rates reported by Harrison et al. [22] for seeds buried at 0 to $20 \mathrm{~cm}$ depth. To match the rate reported by Davis et al. [47], we set the seed decay rate in our model at $25 \%$ for each time-step.

Based on data from Mahoney et al. [42], we set survival of giant ragweed seedlings in rye, due to herbicide application or cultivation, at $10 \%$ (i.e., control efficacy was $90 \%$ ). Survival of giant ragweed seedlings growing with alfalfa was set at 0 , due to the multiple mowing operations associated with hay harvests. Control efficacy of giant ragweed seedlings in corn and soybean was varied in models of the contrasting crop rotation systems.

\subsection{Model Calculations and Scenario Evaluations}

Our primary interest was in potential shifts in giant ragweed seed and plant densities when employing the 5-year rotation system rather than the 2-year system. Of particular interest was determination of the minimal levels of giant ragweed control during corn and soybean phases of the 2-year and 5-year rotations that were needed to prevent increases in seed bank densities of the weed. The analyses were conducted for 30-year periods.

Because soybean was the crop in which giant ragweed fecundity was greatest and because weed mortality from cultivation alone can be insufficient to suppress weed population increases, we also determined population trajectories of giant ragweed when hand weeding was used in the soybean phase of the rotations to supplement cultivation. In reviewing data from 55 studies, Gallandt et al. [6] noted that the mean response to a single cultivation operation was $66 \%$ mortality. Brown and Gallandt [48] reported that when cultivation tools were used sequentially, in most cases the effect of multiple cultivation passes was additive. Consequently, we assumed that each cultivation operation would reduce the density of existing weeds by $66 \%$; two passes would reduce weed density by a cumulative total of $88.4 \%$. Based on these assumptions, we used models to assess the minimum level of weed control that would be needed from hand weeding to supplement $88.4 \%$ control gained from cultivation operations in corn and soybean.

We also used models to investigate how variation in the length of the alfalfa phase within the more diverse rotation system affected giant ragweed population dynamics. Accordingly, in addition to the 2-year corn-soybean and 5-year corn-soybean-rye-alfalfa rotations, we also built models for 3-year, 4-year, and 6-year rotations in which the alfalfa phase spanned 8 months, 20 months, and 44 months, respectively, rather than the 32-month period it occupied in the 5-year rotation (Figure 1). As noted earlier, the alfalfa phase of the 3-year rotation would serve as a cover crop rather than as a harvested hay crop. However, for our modeling analyses, it was useful to maintain the same crop sequence in all of the extended rotations. As with the 2-year and 5-year rotations, we calculated the minimal levels of giant ragweed control that were needed during corn and soybean phases of the rotations to prevent increases in seed bank densities of the weed over 30-year periods.

To characterize differences among rotation systems in temporal patterns of management activities, we calculated a planting interval variation index (PIVI). The PIVI was defined as the coefficient of variation of the number of months between plantings of succeeding crops in each complete rotation 
cycle [14]. We examined the relationship between the PIVI value for each rotation system and the level of control efficacy needed in corn and soybean to prevent increases in giant ragweed seed densities.

Our first-order analyses assumed a high level of giant ragweed control efficacy in rye (90\%), based on results obtained by Mahoney et al. [42] with herbicides applied to winter wheat. Because levels of weed control using cultivation equipment can be considerably lower than with herbicides [6], we conducted a sensitivity analysis to determine the effects of varying levels of giant ragweed control in rye. More specifically, we altered control efficacy in rye in the 5-year rotation from 0 to $100 \%$ and then determined the level of control that would be required in corn and soybean phases of the rotation to prevent increases in giant ragweed seed density.

Post-dispersal consumption of giant ragweed seeds by predators can greatly reduce the quantity of seeds entering the soil seed bank, but the magnitude of seed losses can be highly variable over time and among locations [46]. Therefore, we conducted a sensitivity analysis in which we varied seed predation rates from 0 to $60 \%$ and then determined levels of control efficacy in corn and soybean phases of the 2-year and 5-year rotations needed to prevent increases in giant ragweed seed density. These analyses constituted a means of examining potential complementarities between cropping system diversification, seed predation, and the use of herbicides or cultivation.

\section{Results and Discussion}

Results from our modeling analyses indicate that to prevent an increase in giant ragweed seed density in the soil seed bank, the minimum control efficacy from cultivation or herbicides used in corn and soybean would need to be $99.0 \%$ in a 2-year corn-soybean system but $91.4 \%$ in a 5 -year corn-soybean-rye-alfalfa system (Figure 3a). Thus, the diversified rotation would be better buffered against less-than-perfect weed control during corn and soybean phases. This result is similar to the outcome of modeling analyses conducted on population dynamics of velvetleaf (Abutilon theophrasti Medicus) in a simple corn-soybean rotation and a more diverse corn-soybean-triticale $(\times$ Triticosecale)-alfalfa rotation [49], and it underscores the value of diversified cropping systems in multi-tactic weed management strategies. Additionally, it is important to note that in the 5-year corn-soybean-rye-alfalfa rotation system of the present study, much of the burden of weed control would be shifted from 'direct' tactics, i.e., cultivation and herbicides, to a set of more subtle, 'indirect' tactics that result from differences in crop planting and harvest dates and attendant management practices, such as mowing and hay removal. This might reduce selection for herbicide resistance. Beckie et al. [50] reported that diverse rotations that interspersed annual and perennial crops not only reduced densities of wild oat (Avena fatua L.) but also minimized selection for acetyl-CoA carboxylase-inhibitor herbicide resistance in populations of the weed. 

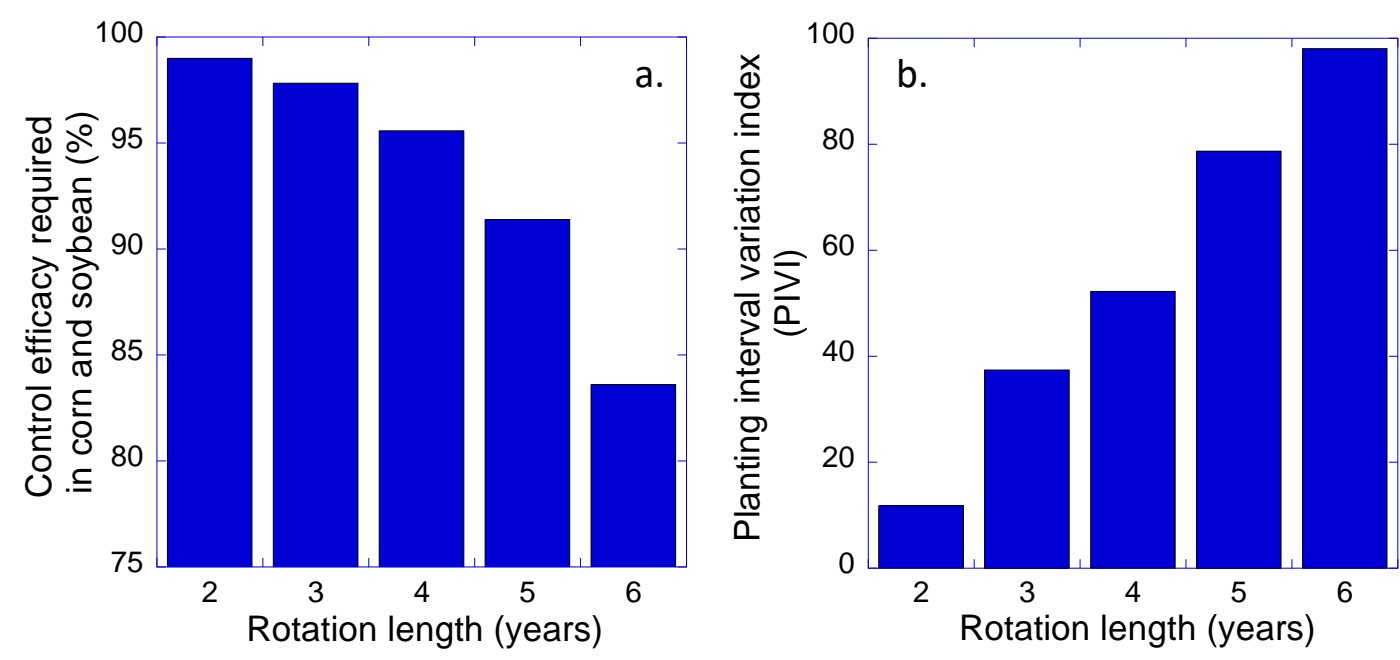

Figure 3. Minimum levels of control efficacy required in corn and soybean to prevent increases in giant ragweed seed densities (a), and planting interval variance index values (PIVI) (b) for the 2-, 3-, 4-, 5-, and 6-year rotation systems.

Using models for the 2-year and 5-year rotation systems, we determined the minimum level of weed control that would be needed from hand weeding in the soybean phase to supplement $88.5 \%$ control gained from cultivation operations used in both the corn and soybean phases. In the 5-year rotation, $44.6 \%$ control efficacy with hand weeding would be required in the soybean phase to prevent increases in giant ragweed populations over time. In contrast, in the 2-year rotation, no level of control efficacy with hand weeding in soybean would be sufficient to prevent increases in giant ragweed density; hand weeding efficacy would need to be at least $91.2 \%$ in both the corn and soybean phases to prevent giant ragweed populations from increasing. These results indicate that for organic producers who lack high levels of control efficacy with cultivation and who seek to minimize the use of labor for hand weeding, diverse rotation systems are required for giant ragweed management.

Increases in the length of the alfalfa phase within a corn-soybean-rye-alfalfa sequence led to reductions in the weed control efficacy that was required in the corn and soybean phases (Figure 3a). Whereas $99.0 \%$ control of giant ragweed was needed in the 2-year corn-soybean rotation, control requirements fell to $97.9 \%$ in the 3-year rotation, $95.6 \%$ in the 4 -year, $91.4 \%$ in the 5 -year rotation, and $83.6 \%$ in the 6 -year rotation. It should be noted that all of the rotations that were greater than two years in length had the same species richness value of 4 (corn, soybean, rye, and alfalfa: Figure 1). Thus, reductions in the requirement for direct weed control were not purely a function of crop species diversity. Adding both rye and alfalfa to the corn and soybean sequence was important for reducing seedling survival and fecundity of giant ragweed, but, in addition, using long-duration stands of alfalfa extended the period in which giant ragweed seeds decayed in the soil and led to reductions in seed bank densities, even without a change in crop species richness. For other weed species whose seeds are more persistent in the soil seed bank than are those of giant ragweed, it should be expected that reductions in seed bank densities through extended periods of alfalfa production would be less marked.

Increases in rotation length were associated with increases in PIVI values (Figure $3 b$ ). Whereas the 2-year rotation had a PIVI value of 11.8, the 6-year rotation had a PIVI value of 98.0, with intermediate PIVI values for the other rotations. More striking, however, was the relationship between PIVI and the weed control efficacy required in corn and soybean phases of the rotations (Figure 4). As PIVI increased, the required level of giant ragweed control in corn and soybean fell at an increasing rate. For the change between the 2-year and 3-year rotations, there was an increase in both crop species richness and PIVI. In contrast, for the 3-, 4-, 5-, and 6-year rotations, crop species richness was identical and only the intervals between planting dates changed. Thus, PIVI was more useful than species number in predicting the weed suppression ability of given crop rotation. These modeling outcomes accord with 
the theoretical insight provided by Gaba et al. [15] and corroborate the results of the meta-analysis of empirical data reported by Weisberger et al. [14].

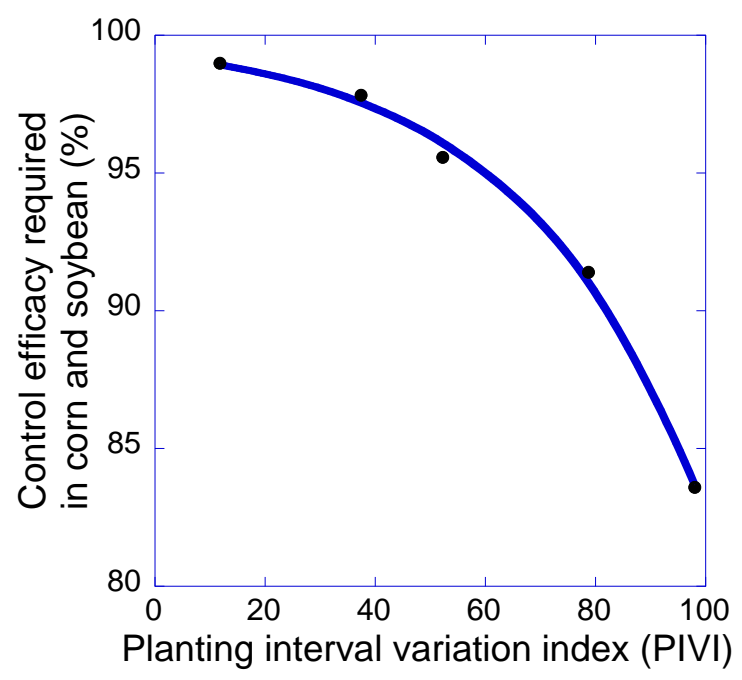

Figure 4. The relationship between planting interval variation index (PIVI) and the minimum level of control efficacy required in corn and soybean to prevent increases in giant ragweed seed density. As shown in Figure 3b, PIVI values differed among the 2-, 3-, 4-, 5-, and 6-year rotation systems.

A reduction in giant ragweed control efficacy in the rye phase of the 5-year rotation had only a slight effect on the level of control required in corn and soybean phases of the rotation needed to prevent an increase in seed density of the weed (Figure 5). Whereas $91.4 \%$ control was required in corn and soybean to prevent increases in giant ragweed seed density when $90.0 \%$ control was achieved in the rye phase, the control requirement in corn and soybean increased only slightly to $93.2 \%$ when there was $0 \%$ control of the weed in the rye phase of the rotation (Figure 5). This result can be explained, in large part, by the low fecundity of giant ragweed plants surviving in rye $\left(3\right.$ seeds plant $\left.{ }^{-1}\right)$, and it highlights the importance of considering the effects of management practices and crop competition on both weed survival and fecundity.

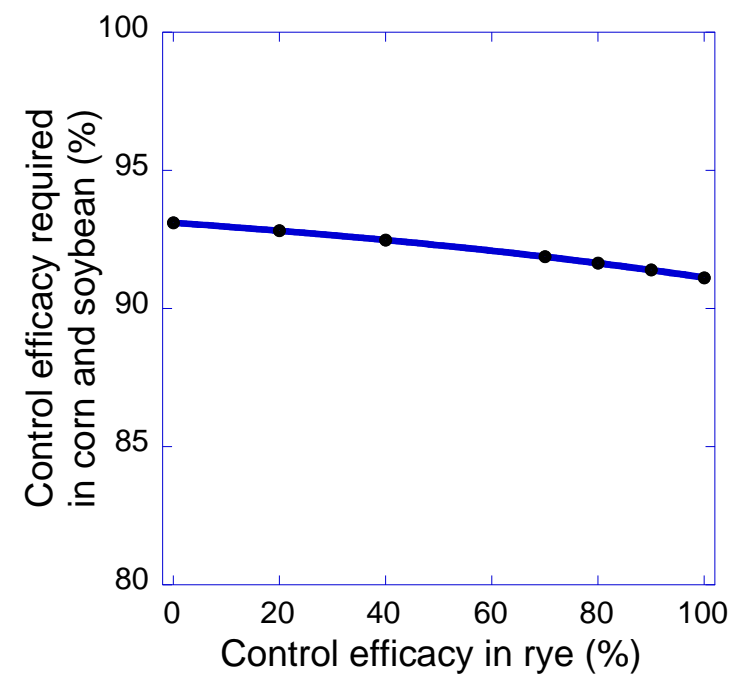

Figure 5. The relationship between weed control efficacy in the rye phase of the 5-year rotation and the minimum level of control efficacy required in corn and soybean to prevent increases in giant ragweed seed density. 
Sensitivity analysis indicated that for both the 2-year and 5-year rotations, increases in losses of giant ragweed seeds to predators reduced the level of control efficacy in corn and soybean that was required to prevent increases in seed densities of the weed (Figure 6). However, this effect was stronger in the 5-year rotation compared with the 2-year rotation (Figure 6). For the 2-year rotation, 99.6\% control efficacy was required in corn and soybean when there were no losses of seeds to predators, and $99.0 \%$ control efficacy was required when the seed predation rate was $60 \%$. In contrast, for the 5-year rotation, $96.8 \%$ control efficacy was required when there were no losses of seeds to predators, whereas $91.4 \%$ efficacy was required with a seed predation rate of $60 \%$. These results indicate that developing strategies, such as delaying tillage, to enhance weed seed consumption by predators is desirable [51], especially in the context of diversified rotation systems that challenge weed populations with multiple stress and mortality factors that act as 'many little hammers' [49].

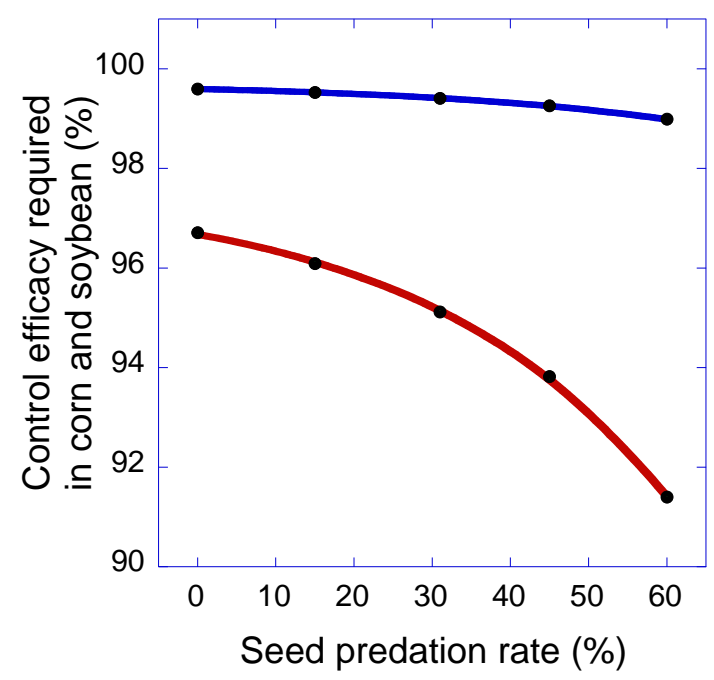

Figure 6. The relationship between seed predation rate and the minimum level of control efficacy required in corn and soybean to prevent increases in giant ragweed seed density in the 2-year (blue line) and 5-year (red line) rotations.

As noted earlier, our modeling analyses are subject to multiple caveats. In particular, our models did not include density-dependent effects on weed survival and fecundity rates and lacked depth-structured seedbanks. Our assumptions for values of giant ragweed demographic parameters in different crops were constrained by a paucity of relevant scientific reports. In addition, while we sought to create agronomically plausible cropping systems, we ignored financial considerations that would suggest economically optimal systems. Nonetheless, we contend that the modeling analyses we conducted for giant ragweed management highlight the value of diversified rotations that include both annual and perennial crops, and call attention to the critically important role of temporal variation in management activities. Those themes merit more attention in future field experiments and on-farm trials.

Supplementary Materials: The following are available online at http://www.mdpi.com/2073-4395/10/2/262/s1, Figure S1: Diagram for the 2-year rotation model used in STELLATM, Figure S2: Diagram for the 5-year rotation model used in STELLATM, Table S1: Equations for the 2-year rotation model used in STELLATM, Table S2: Equations for the 5-year rotation model used in STELLATM.

Author Contributions: M.L. and V.A.N. conceptualized the manuscript. M.L. conceived the general modeling framework and developed models for the different rotation systems in STELLA ${ }^{\text {TM }}$. M.L. and V.A.N. evaluated the model mechanics and outputs and corrected the models. M.L and V.A.N. wrote the text of the manuscript and reviewed and edited it. M.L. and V.A.N. prepared the graphics. All authors have read and agreed to the published version of the manuscript. 
Funding: Funding support for V.A.N was provided by the U.S. National Science Foundation Research Traineeship DataFEWSion Program; the Foundation for Food and Agricultural Research; and the H.A. Wallace Chair for Sustainable Agriculture.

Acknowledgments: The authors gratefully acknowledge the many members of Practical Farmers of Iowa who provided information and questions concerning crop rotation and giant ragweed management.

Conflicts of Interest: The authors declare no conflict of interest.

\section{References}

1. Oerke, E.C. Crop losses to pests. J. Agric. Sci. 2006, 144, 1-43. [CrossRef]

2. Heap, I. Trends in the development of herbicide-resistant weeds. In Integrated Weed Management for Sustainable Agriculture; Zimdahl, R.L., Ed.; Burleigh Dodds Science Publishing: Cambridge, UK, 2018; pp. 169-192.

3. Preston, C. Assessing and minimizing the environmental effects of herbicides. In Integrated Weed Management for Sustainable Agriculture; Zimdahl, R.L., Ed.; Burleigh Dodds Science Publishing: Cambridge, UK, 2018; pp. 133-167.

4. Westwood, J.H.; Charudattan, R.; Duke, S.O.; Fennimore, S.A.; Marrone, P.; Slaughter, D.C.; Swanton, C.; Zollinger, R. Weed management in 2050: Perspectives on the future of weed science. Weed Sci. 2018, 66, 275-285. [CrossRef]

5. Gonsolus, J.L.; Buhler, D.D. A risk management perspective on integrated weed management. J. Crop Prod. 1999, 2, 167-187. [CrossRef]

6. Gallandt, E.R.; Brainerd, D.; Brown, B. Developments in physical weed control. In Integrated Weed Management for Sustainable Agriculture; Zimdahl, R.L., Ed.; Burleigh Dodds Science Publishing: Cambridge, UK, 2018; pp. 261-283.

7. Liebman, M.; Davis, A.S. Managing weeds in organic farming systems: An ecological approach. In Organic Farming: The Ecological System; Francis, C., Ed.; American Society of Agronomy: Madison, WI, USA; Crop Science Society of America: Madison, WI, USA; Soil Science Society of America: Madison, WI, USA, 2009; pp. 173-195.

8. Mortensen, D.A.; Egan, J.F.; Maxwell, B.D.; Ryan, M.R.; Smith, R.G. Navigating a critical juncture for sustainable weed management. Bioscience 2012, 62, 75-84. [CrossRef]

9. Bagavathiannan, M.V.; Davis, A.S. An ecological perspective on managing weeds during the great selection for herbicide resistance. Pest Manag. Sci. 2018, 74, 2277-2286. [CrossRef] [PubMed]

10. Davis, A.S. Weed ecology and population dynamics. In Integrated Weed Management for Sustainable Agriculture; Zimdahl, R.L., Ed.; Burleigh Dodds Science Publishing: Cambridge, UK, 2018; pp. 3-28.

11. Beckie, H.J.; Harker, K.N. Our top 10 herbicide-resistant weed management practices. Pest Manag. Sci. 2017, 73, 1045-1052. [CrossRef] [PubMed]

12. Teasdale, J.R. The use of rotations and cover crops to manage weeds. In Integrated Weed Management for Sustainable Agriculture; Zimdahl, R.L., Ed.; Burleigh Dodds Science Publishing: Cambridge, UK, 2018; pp. 227-260.

13. Liebman, M.; Gallandt, E.R. Many little hammers: Ecological management of crop-weed interactions. In Ecology in Agriculture; Jackson, L.E., Ed.; Academic Press: Orlando, FL, USA, 1997; pp. 287-339.

14. Weisberger, D.A.; Nichols, V.; Liebman, M. Does diversifying crop rotations suppress weeds? A meta-analysis. PLOS ONE 2019. [CrossRef]

15. Gaba, S.; Fried, G.; Kazakou, E.; Chauvel, B.; Navas, M.-L. Agroecological weed control using a functional approach: A review of cropping systems diversity. Agron. Sustain. Dev. 2014, 34, 103-119. [CrossRef]

16. Levins, R. The strategy of model building in population biology. Am. Sci. 1966, 54, 421-431.

17. Regnier, E.E.; Harrison, S.K.; Loux, M.M.; Holloman, C.; Venkatesh, R.; Diekmann, F.; Taylor, R.; Ford, R.A.; Stoltenberg, D.E.; Hartzler, R.G.; et al. Certified Crop Advisors' perceptions of giant ragweed (Ambrosia trifida) distribution, herbicide resistance, and management in the Corn Belt. Weed Sci. 2016, 64, 361-377. [CrossRef]

18. Bazzaz, F.A. Demographic consequences of plant physiological traits: Some case studies. In Perspectives on Plant Population Ecology; Dirzo, R., Surukhán, J., Eds.; Sinauer Associates: Sunderland, MA, USA, 1984; pp. 324-346. 
19. Harrison, S.K.; Regnier, E.E.; Schmoll, J.T.; Webb, J.E. Competition and fecundity of giant ragweed in corn. Weed Sci. 2001, 49, 224-229. [CrossRef]

20. Goplen, J.J.; Sheaffer, C.C.; Becker, R.L.; Coulter, J.A.; Breitenback, F.R.; Behnken, L.M.; Johnson, G.A.; Gunsolus, J.L. Giant ragweed (Ambrosia trifida) seed production and retention in soybean and field margins. Weed Technol. 2016, 30, 246-253. [CrossRef]

21. Harrison, S.K.; Regnier, E.E.; Schmoll, J.T. Postdispersal predation of giant ragweed (Ambrosia trifida) seed in no-tillage corn. Weed Sci. 2003, 51, 955-964. [CrossRef]

22. Harrison, S.K.; Regnier, E.E.; Schmoll, J.T.; Harrison, J.M. Seed size and burial effects on giant ragweed (Ambrosia trifida) emergence and seed demise. Weed Sci. 2007, 55, 16-22. [CrossRef]

23. Goplen, J.J.; Sheaffer, C.C.; Becker, R.L.; Coulter, J.A.; Breitenback, F.R.; Behnken, L.M.; Johnson, G.A.; Gunsolus, J.L. Seedbank depletion and emergence patterns of giant ragweed (Ambrosia trifida) in Minnesota cropping systems. Weed Sci. 2017, 65, 52-60. [CrossRef]

24. Karlen, D.L.; Hurley, E.G.; Andrews, S.S.; Cambardella, C.A.; Meek, D.W.; Duffy, M.D.; Mallarino, A.P. Crop rotation effects on soil quality at three northern Corn/Soybean Belt locations. Agron. J. 2006, 98, 484-495. [CrossRef]

25. Broussard, W.P.; Turner, R.E.; Westra, J.V. Do federal farm policies influence surface water quality? Agric. Ecosyst. Environ. 2012, 158, 103-109. [CrossRef]

26. Hatfield, J.L.; McMullen, L.D.; Jones, C.S. Nitrate-nitrogen patterns in the Raccoon River Basin related to agricultural practices. J. Soil Water Conserv. 2009, 64, 190-199. [CrossRef]

27. US. Department of Agriculture-National Agricultural Statistics Service. 2017 Census of Agriculture; USDA-NASS: Washington, DC, USA, 2019. Available online: https://www.nass.usda.gov/Publications/ AgCensus/2017/ (accessed on 11 February 2020).

28. Alexander, R.B.; Smith, R.A.; Schwarz, G.E.; Boyer, E.W.; Nolan, J.V.; Brakebill, J.W. Differences in phosphorus and nitrogen delivery to the Gulf of Mexico from the Mississippi River Basin. Environ. Sci. Technol. 2008, 42, 822-830. [CrossRef]

29. Heathcote, A.J.; Filstrup, C.T.; Downing, J.A. Watershed sediment losses to lakes accelerating despite agricultural soil conservation efforts. PLoS ONE 2013, e53554. [CrossRef]

30. Sulc, R.M.; Tracy, B.F. Integrated crop-livestock systems in the U.S. Corn Belt. Agron. J. 2007, 99, 335-345. [CrossRef]

31. Poffenbarger, H.; Artz, G.; Dahlke, G.; Edwards, W.; Hanna, M.; Russell, J.; Sellers, H.; Liebman, M. An economic analysis of integrated crop-livestock systems in Iowa, USA. Agric. Syst. 2017, 157, 51-69. [CrossRef]

32. Goplen, J.J.; Coulter, J.A.; Sheaffer, C.C.; Becker, R.L.; Breitenbach, F.R.; Behnken, L.M.; Gonsulus, J.L. Economic performance of crop rotations in the presence of herbicide-resistant giant ragweed. Agron. J. 2018, 110, 260-268. [CrossRef]

33. Hunt, N.; Hill, J.; Liebman, M. Cropping system diversity effects on nutrient discharge, soil erosion, and agronomic performance. Environ. Sci. Tech. 2019, 53, 1344-1352. [CrossRef]

34. Hunt, N.; Hill, J.; Liebman, M. Reducing freshwater toxicity while maintaining weed control, profits, and productivity: Effects of increased crop rotation diversity and reduced herbicide usage. Environ. Sci. Technol. 2017, 51, 1707-1717. [CrossRef]

35. Hunt, N.D.; Liebman, M.; Thakar, S.K.; Hill, J.D. Fossil energy use, climate change impacts, and air quality-related human health damages of conventional and diversified cropping systems in Iowa, USA. Environ. Sci. Technol. 2020, in press.

36. Mallory, E.; Molloy, T. Winter Rye Variety Trial: 2017 Results; University of Maine Cooperative Extension: Orono, ME, USA, 2018; Available online: https:/extension.umaine.edu/grains-oilseeds/wp-content/uploads/ sites/16/2018/05/Winter-Rye-Variety-Trial-2017-Results.pdf (accessed on 11 February 2020).

37. Wiersma, J.; Wells, S.; García y García, A. Winter Rye Field Crop Trials Results; Minnesota Agricultural Experiment Station: St. Paul, MN, USA, 2018; Available online: https://www.maes.umn.edu/sites/maes.umn. edu/files/2018_winter_rye_final.pdf (accessed on 11 February 2020).

38. Wilde, P.; Schmiedchen, B.; Menzel, J.; Gordillo, A.; Fowler, D.B. Brasetto hybrid winter rye. Can. J. Plant Sci. 2018, 98, 195-198. [CrossRef]

39. McGhee, M.L.; Stein, H.H. Apparent and standardized ileal digestibility of AA and starch in hybrid rye, barley, wheat, and corn fed to growing pigs. J. Anim. Sci. 2018, 96, 3319-3329. [CrossRef] 
40. Smit, M.N.; Zhou, X.; Landero, J.L.; Young, M.G.; Beltranena, E. Hybrid Rye Replacing Wheat Grain for Hogs. Available online: https://pdfs.semanticscholar.org/f7ae/d9b2e8750b6b1824de72f5bb7eaa24b08983.pdf (accessed on 11 February 2020).

41. Barnes, D.K.; Goplen, B.P.; Baylor, J.E. Highlights in the USA and Canada. In Alfalfa and Alfalfa Improvement; Hanson, A.A., Barnes, D.K., Hill, R.R., Jr., Eds.; American Society of Agronomy-Crop Science Society of America-Soil Science Society of America: Madison, WI, USA, 1988; pp. 1-24.

42. Mahoney, K.J.; McNaughton, K.E.; Sikkema, P.H. Control of glyphosate-resistant giant ragweed in winter wheat. Weed Technol. 2015, 29, 868-873. [CrossRef]

43. Wortman, S.E.; Davis, A.S.; Schutte, B.J.; Lindquist, J.L.; Cardina, J.; Felix, J.; Sprague, C.L.; Dille, J.A.; Ramirez, A.H.M.; Reicks, G.; et al. Local conditions, not regional gradients, drive demographic variation of giant ragweed (Ambrosia trifida) and common sunflower (Helianthus annuus) across northern U.S. Maize Belt. Weed Sci. 2012, 60, 440-450. [CrossRef]

44. Butler, R.A.; Brouder, S.M.; Johnson, W.G.; Gibson, K.D. Response of four summer annual weed species to mowing frequency and height. Weed Technol. 2013, 27, 798-802. [CrossRef]

45. Glettner, C.E.; Stoltenberg, D.E. Noncompetitive growth and fecundity of Wisconsin giant ragweed resistance to glyphosate. Weed Sci. 2017, 63, 273-281. [CrossRef]

46. Davis, A.S.; Taylor, E.C.; Haramoto, E.R.; Renner, K.A. Annual postdispersal weed seed predation in contrasting field environments. Weed Sci. 2013, 61, 296-302. [CrossRef]

47. Davis, A.S.; Fu, X.; Schutte, B.J.; Berhow, M.A.; Dalling, J.W. Interspecific variation in persistence of buried weed seeds follows trade-offs among physiological, chemical, and physical seed defenses. Ecol. Evol. 2016, 6, 6836-6845. [CrossRef]

48. Brown, B.; Gallandt, E.R. Evidence of synergy with 'stacked' intrarow cultivation tools. Weed Res. 2018, 58, 284-291. [CrossRef]

49. Westerman, P.R.; Liebman, M.; Menalled, F.D.; Heggenstaller, A.H.; Hartzler, R.G.; Dixon, P.M. Are many little hammers effective? Velvetleaf (Abutilon theophrasti) population dynamics in two- and four-year crop rotation systems. Weed Sci. 2005, 53, 382-392. [CrossRef]

50. Beckie, H.J.; Johnson, E.N.; Leeson, J.Y.; Shirriff, S.W.; Kapiniak, A. Selection and evolution of acetyl-CoA carboxylase (ACC)-inhibitor resistance in wild oat (Avena fatua L.) in a long-term alternative cropping systems study. Can. J. Plant Sci. 2014, 94, 727-731. [CrossRef]

51. Westerman, P.R.; Liebman, M.; Heggenstaller, A.H.; Forcella, F. Integrating measurements of seed availability and removal to estimate weed seed losses due to predation. Weed Sci. 2006, 54, 566-574. [CrossRef] 